\title{
INCIDENCE OF LEPROSY IN CHILDREN BORN AT NGOMAHURU, S. RHODESIA
}

Bernard Moiser, M.B. (Lond.), M.R.C.S., L.R.C.P., D.P.H.

During the past few months, I have been examining children, born at Ngomahuru, for signs of the disease.

All had been breast fed at Ngomahuru by the mothers for one 
year after birth, without any special precautions having been taken, and had then been sent away to healthy relatives or friends, after weaning, which was carried out gradually before the year was finished. Their ages ranged from 16 years, downwards. Of 42 children so examined, only one (twin) has developed the disease, whilst 2 others have suspicious signs not supported by microscope findings.

It thus appears to be a fairly safe practice to allow children to be brought up by their mothers for a year, though there can be no doubt that the ideal is to separate the child from the mother at birth, to be breast-fed by a wet nurse. But this practice is abhorrent to the native women of this country and it has been found quite impossible to persuade a woman to breast-feed another's child.

It is equally impossible to induce the mother to allow the child to be bottle fed. 